卷或 百第集九第誌雜學地

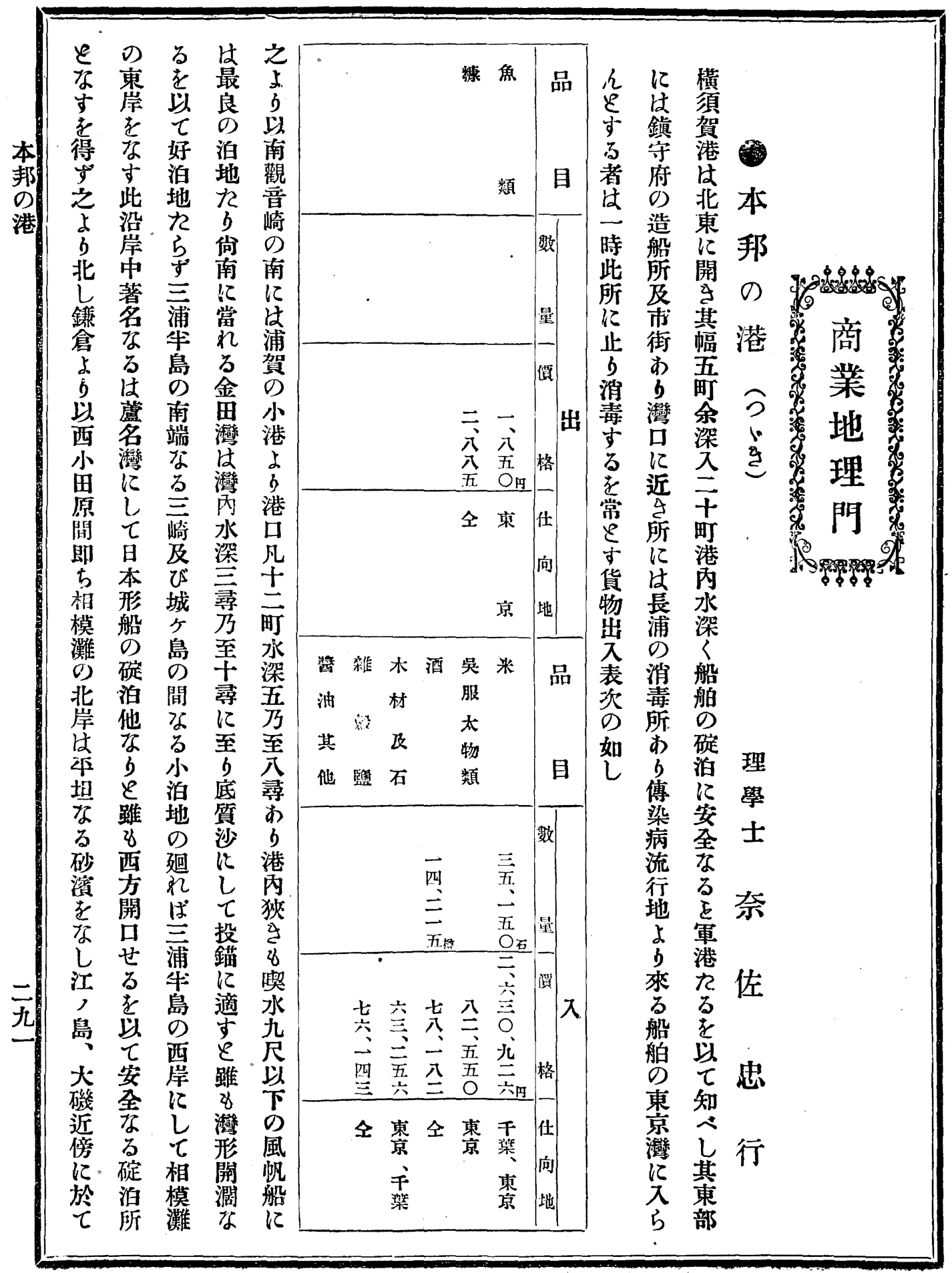




\section{忩: 墢五十月六年十三治明}

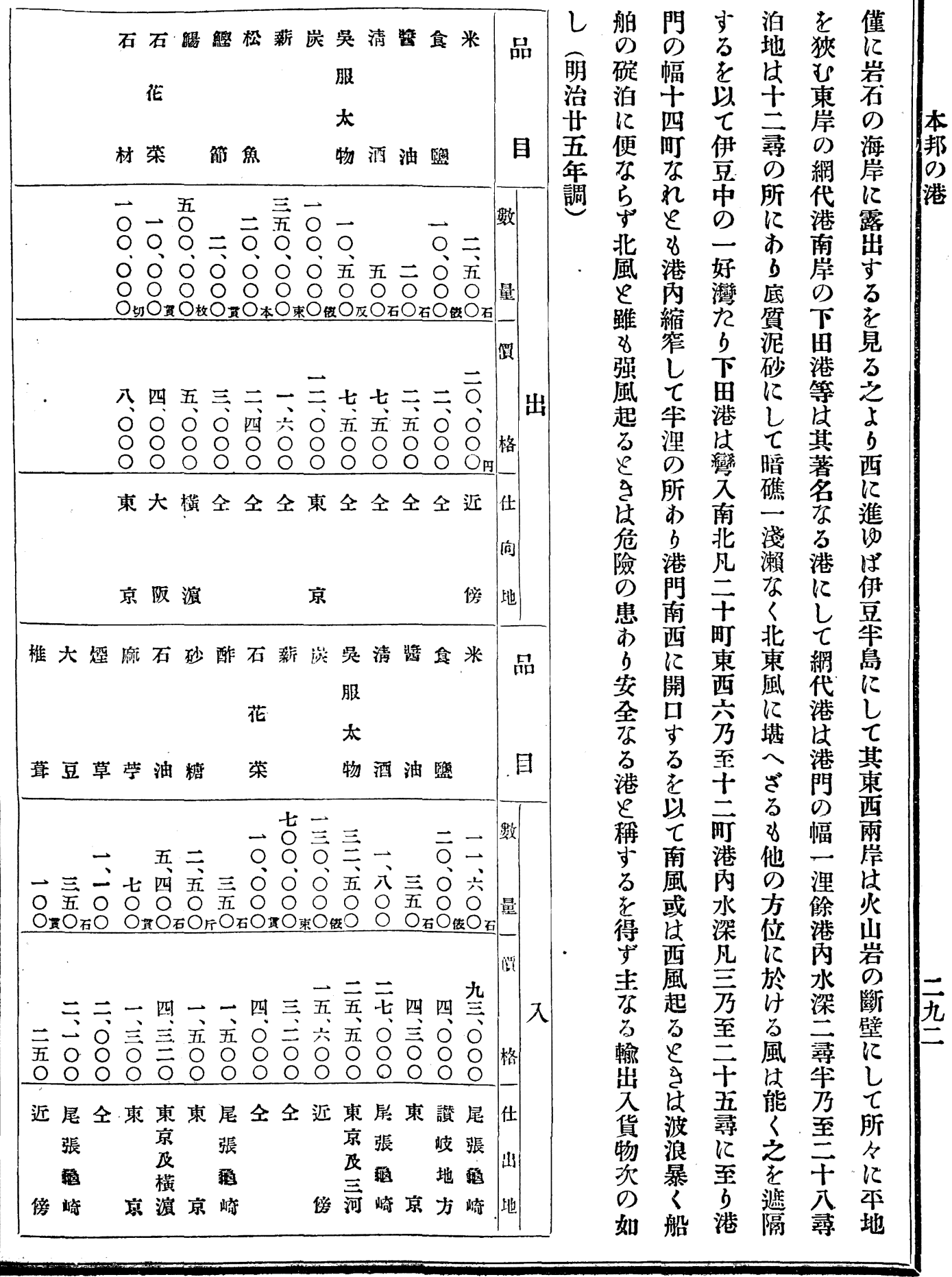


矮武百第集九第誌雜學地

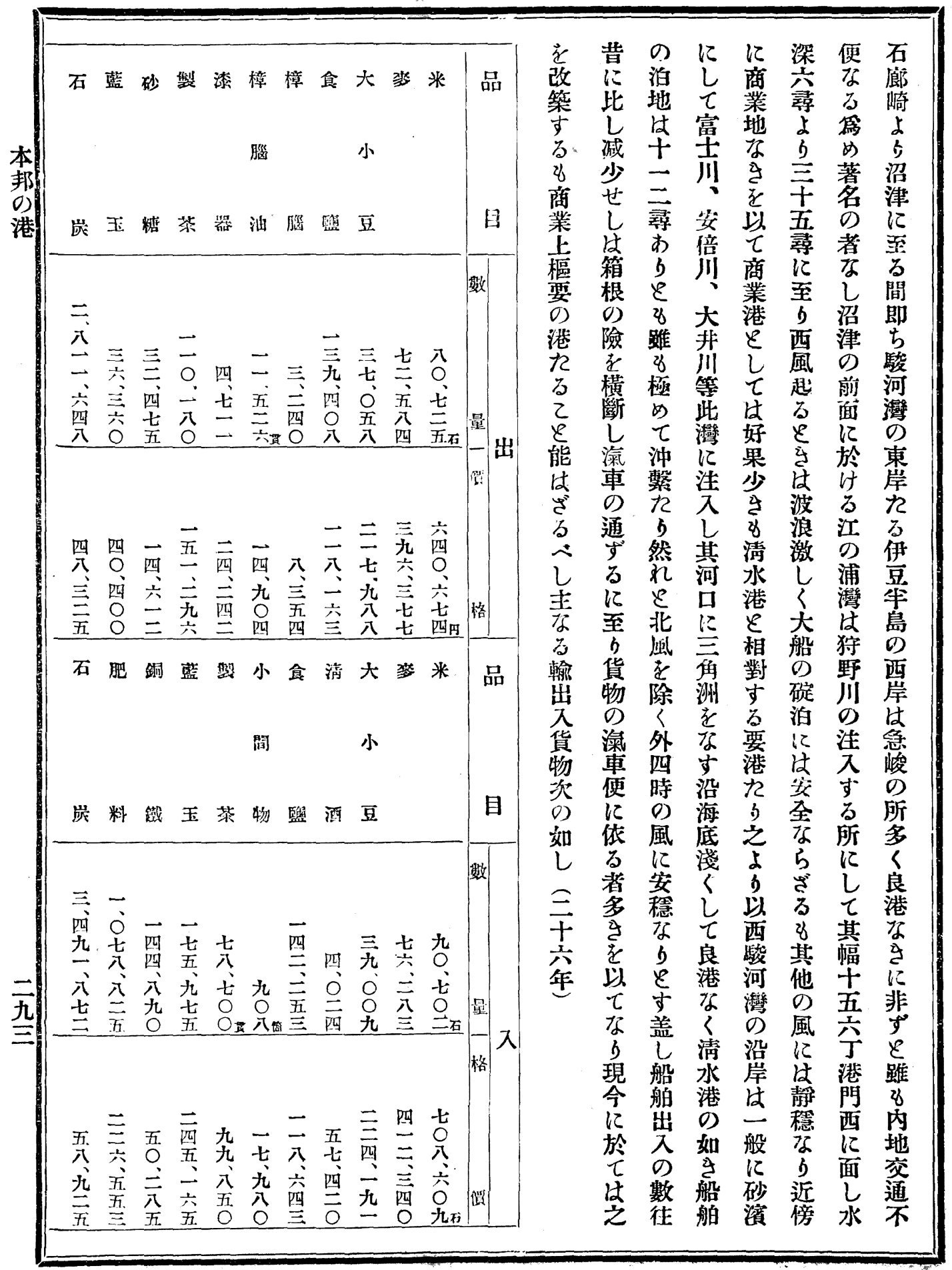


兌墢日五十月亲年十三治明

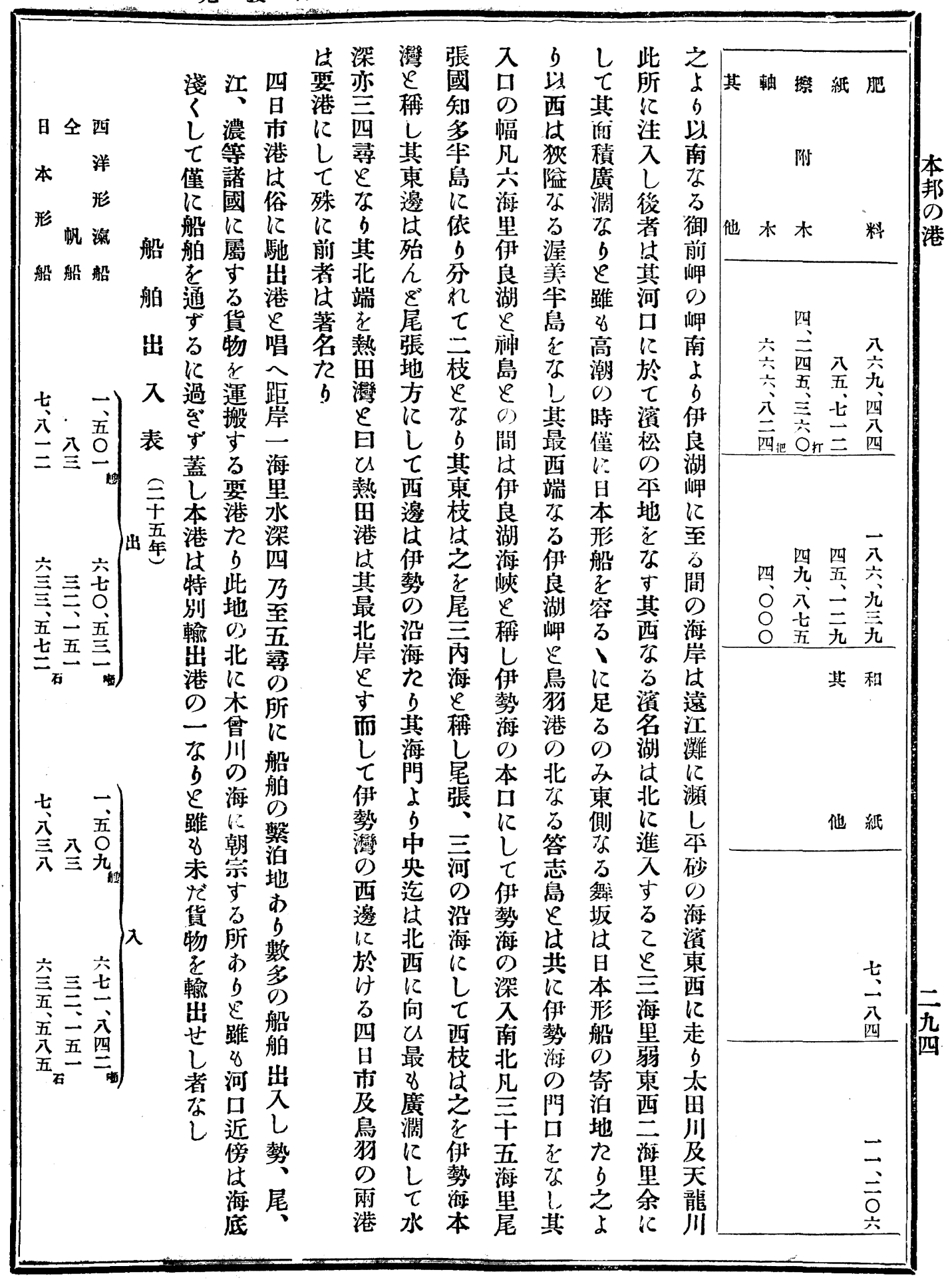

